\title{
A CASA DOS EXPOSTOS: SINAIS DE IDENTIFICAÇÃO
}

\author{
Hilda Agnes Hübner Flores *
}

O presente trabalho faz parte de uma pesquisa em andamento, sobre a qual já foi publicado artigo - A Casa dos Expostos - de autoria de Moacyr Flores, no n $\mathrm{XI} / 1985$ desta Revista.

A pesquisa trata da Casa dos Expostos mantida pela Santa Casa de Misericórdia de Porto Alegre, no período de 1838 a 1934, período esse em que atendeu 2500 crianças abandonadas por seus pais ou responsáveis para receberem criação aos cuidados da Santa Casa e às expensas, em grande parte, da caridade pública.

Estas crianças, a maioria recém-nascida, estariam relega das ao completo anonimato, não fossem os cuidados da Santa Casa de anotar criteriosamente nos Livros de Matrícula e Registro da Casa dos Expostos, o enxoval e outros objetos que as acompanhavam. Constituem estes objetos, mais que meros "sinais de identificação", verdadeiro espelho da sociedade oitocentista, retratando usos e valores, contexto sócio-econômico, preceitos religiosos, crenças, conceito de caridade, sanções sociais, dependência econômica interna e externa, nível cultural, habilidades artesanais, relação de dependência na socie dade patriarcal e outros.

Os dados aqui usados referem-se ao século XIX, carecendo a pesquisa ainda de fichamento de dados até 1934 e confron to com informes de outras fontes, como Livros Tombo e de Registro pertencentes a outras instituições da época.

Isto dito, passamos a algumas considerações referentes aos Sinais de Identificação, constituídos basicamente de "enxoval" e de comunicação escrita (bilhetes ou cartas), que acompanhavam os menores expostos, implorando receber da Casa da Roda a caridade da criação e formação tolhidas pelas imposições sociais que incitavam o machismo mas con denavam o fruto de amores ilícitos e descuidava da assistência promocional às camadas inferiores da população. 
1. Enxoval. Deve ser analisado sob diferentes aspectos: peças de vestuário, qualidade de tecido, adornos e adereços vários, como in dicadores dos padrões sócio-culturais usuais no período oitocentista.

1.1. Peças de vestuário. As mais freqüentes eram: cueiro e mantilha (quase sempre do mesmo tecido e cor: baeta encarnada), camisa, cinteiro, toalha, pano (ou trapo), lenço (de três ou quatro pontas, muitas vezes com iniciais bordadas em uma das pontas; servia para envolver a cabeça, que devia estar sempre bem protegida), timão (a partir do terceiro quartel do séc. XIX, substituído por casaquinho), barre te ou touca, camisola, esta mais usual na segunda metade do século XIX.

Era menor a incidência de crianças que vestiam ou traziam trouxa com: meias, corpinho, lençol, travesseiro (raros), babador, vestidinho, sapato e botins (muito raro), rodaque (colete), tira de umbigo e fraldas, estas sempre muito parcimoniosas (uma dúzia era raridade), in dício de higiene precária, certamente um dos fatores da elevadíssima mortandade infantil. No mínimo duas em cada três crianças morriam, elevando-se este índice a $45 \%$ no período farroupilha. Com o uso de amas de leite, a mamadeira é verdadeira excessão, aparecendo a primeira e uma das raras na década de 1860.

Sem constituírem propriamente "peças de vestuário", crianças de enxoval muito humilde, ou inexistente, vinham enroladas em saia usada de mulher, cortina ou colcha velha, manga de camisa ou trapos velhos, numa demonstração de extrema miséria.

Entre os malefícios inerentes à guerra está o desequilíbrio sócio-econômico que desarticula a sociedade e abala a estrutura familiar. Foi o que se verificou nas três guerras que o Império sustentou no sul: a Farroupilha, a Platense e a do Paraguai.

O agravo de problemas sociais repercutiu na Casa da Roda, pelo aumento quantitativo de crianças abandonadas, conforme mostra o gráfico anexo: em 1843, após a passagem por Porto Alegre da tropa de 10.000 homens que, sob o comando de Caxias, veio apaziguar a Província; no primeiro lustro de 1850 , com o deslocamento de tropas para lutar contra Oribe e Aguirre; e por volta de 1866 e 1867, com tropas de voluntários da pá tria acantonadas em Porto Alegre, em caminho para o cenário da guerra paraguaia.

Nesses períodos de instabilidade social, crianças eram abandonadas na Roda envoltas em poncho, xerga ou enxerga, pedaço de cobertor ou de capote de soldado, como, por exemplo, as gêmeas Percília e Cecília, expostas em 5.11.1864, vestindo "camisa, cueiro, cinfeiro e touca e embrulhadas em cabeção de capote de soldado, de saragossa" (Livro de Registro 2G da 
Santa Casa de Misericórdia, matrículas 1211 e 1212).

A repercussão sócio-econômica ultrapassava o período estrito da guerra, conforme indica o recém-nascido Cesefredo, abandonado um ano e meio após o término da Guerra dos Farrapos, em 2.11.1846, enrolado em "um pedaço de pano azul de capote de soldado" (L. Reg. 1G, matr. 340).

1.2. Tipo de tecido. A primeira fábrica de tecelagem no Rio Grande do Sul, e que veio a ter repercussão internacional, foi a do fundador da Colônia de São Lourenço, Jacob Theingantz, criada em Rio Grande em 1874. O Brasil, carente de indústria em geral, importava toda a sorte de tecidos, fornecidos principalmente pela Inglaterra, que industrializava matéria-prima de seu imenso império colonial.

O enxoval dos expostos da Casa da Roda refletiu a realidade oitocentista de recursos inexistentes no mercado interno, quer fossem roupas novas de crianças abandonadas por razões não econômicas, quer se tratasse de enxoval humilde, de tecido roto, aproveitado em segunda mão.

Tecidos que aparecem com maior freqüência são: algodão, baeta (lã grosseira), baetilha (mais fina que a anterior), cambraia, cambrainha, cassa (tecido transparente de linho ou algodão), chita, escócia ou escórcia, filó, lãzinha, meia, morim, musselina (espécie de chita leve com algum lavrado), pano, pelúcia, riscado (algodão) e seda.

Com incidência pouco menor segue: algodãozinho, casemira, ganga (tecido grosseiro), merinó (de lã de carneiro), nobreza (de 1859 em diante), fustão (década de 1850 em diante), paninho, riscadinho, setim, malha de tã, brim, chita e Pompadour (na década de 1880 , de acentuada influência francesa, a Casa Glausen, na rua dos Andradas, anunciava "chita a Pompadour" recém-chegada de Paris), damasco (procedente da cidade turca homônima), garça (tela rala), linho, madapolão (lã branca e consistente), sarja (seda ou lã entrançada), tafe tá e veludo.

Com pequena freqüência, apareciam enxovais confeccionados em alpaca (tecido da lã do mamífero homônimo), bretanha (desde 1868), chamelote (tecido de pêlo ou lã), cambraeta (desde 1876), camelão (impermeável de pele de cabra), flanela, lapim (sarja de seda fina), berege (lã dos Pirineus), belbutina (tecido de lã aveludado), cassineta (lã fina e leve), saragoça (tecido grosseiro de lã preta), tarbatana (em 1874 pela primeira vez), setineta, xalim.

Quanto às cores dos tecidos, foram registradas todas as cores habituais em nossos dias: branco, azul, amarelo, rosa, roxo, ver de, encarnado, escarlate, sulferino, vinho, carmim, púrpura, pre to. Preto e roxo estavam muitas vezes conjuga das em uma única peça infantil. $O$ roxo era cor bastante usual na década de 1840, sendo mais freqüentes timões e cinteiros de chita dessa cor, 
além de fitas e cercaduras ornamentais.

Usadas eram igualmente as cores havana e parda, e outras de nomenclatura mais estranha, como: cor ganga, de suspiro, de rapé, de flor de laranjeira, de flor de alecrim, de cravo, de sangue de boi, ferrete e barege.

1.3. Adornos de vestuário. Há períodos, como o compreendido entre os anos de 1850 a 1858 e entre 1882 a 1885 , em que o registro de enxoval é omisso ou assentado em traços muito genéricos. Outras vezes, dependendo do espírito observador da pessoa encarrega da, são arrolados com minúcia as peças do vestuário com farta e interessante descrição de adornos, que dizem das "prendas domésticas", de domínio obrigatório para a mulher oitocentista.

Para enfeitar a roupinha do nenê, houve emprego de fitas estreitas, de trabalhos em crochê (segunda metade do século em diante), de bordados, debruns ou cercaduras. Nos enxovais pobres era comum cercadura de tecido, com combinações de cores pouco felizes, como: casaquinho xadrez roxo com cercadura preta. Gola, cabeção e punhos eram os mais decorados, recebendo barras bordadas, rendados, crochê ou cercadura.

Gregas, cadarços e fitas de largura média tinham emprego menos freqüente. Fitas largas eram bastante raras, bem como crivo, gorgurão, trancelim, vidrilhos e franjas.

Como exemplo de enxoval com riqueza de acabamento citamos o de Gelsumira, exposta na madrugada de 5.11.1874, vestindo

\begin{abstract}
"1 camisa de cambraia com peito e punhos bordados e cabeção de filó; 1 cueiro de baeta encarnada lavrada com nobreza cor flor de alecrim; 1 mantilha de baeta encarnada barrada com lãzinha azul clara; 1 cinteiro de setim branco guarnecido com fita sulferina; 1 toalha de musselina com babados de escócia; 1 barrete de meia aberta; 1 touca de nobreza cor de alecrim enfeitada com renda e grega de seda preta e fita roxa; 1 saiote de setim carmezim enfeitado com grega e franja de seda" (L. Reg. 2G, matr. 1667).
\end{abstract}

1.4. Adereços vários. Cerca de $10 \%$ das crianças expostas no século passa do estavam acompanhadas de algum adorno ou adereço de in dividualização ou identificação, na pretensa tentativa, por parte de quem as abandonava, de estabelecer vínculo posterior.

Estes objetos, de adorno ou proteção, eram trazidos ao pescoço ou braço(s) e raramente na cintura, atados por meio de fitas, linhas de algodão ou seda, cordões ou correntes, às vezes, de ouro ou prata. Tinham forma variada; corações, contas, figas, medalhas ou verônicas, meias luas, búzios, breves, relicários, cruzes, molhos de arruda ou cabeças de maçanilha, fita 
com dísticos, trança de cabelo, sino, aro, chave e moedas. Estas eram, na maioria das vezes, portuguesas, de diversos valores (tostão, mil réis), mas havia-as também norte-americanas, canadenses, irlandesas, alemãs e outras nacionalidades. Adelina, por exemplo, exposta em 6.3.1864, trouxe ao pescoço:

\begin{abstract}
"uma moeda americana de ouro no valor de 2 mil réis, cunhada em 1854; uma moeda de prata espanhola, 120 réis, cunhada em 1807 no reinado de Carlos IV, enfiada com contas azuis" (L. Reg. 2G, matr. 1182).
\end{abstract}

Era comum a junção de vários a de reços de significado distinto, como coração e meia lua, aro e búzios, etc. Belmira, exposta em 30.6.1843, trouxe amarrado ao pescoço "uma enfiada de corais com um coração e uma figa de ouro, pequenos" (L. Reg. 1G, matr. 195). Já Ricardo Só, abandonado aos 6 meses de idade, em 1.9.1862 e com bilhete indicando ser este seu nome, veio "melhor protegido" com

\footnotetext{
"um dente de guará, um dente de cão, uma figa de chifre, 1/4 de lua de prata e uma figa pequena de ouro, uma enfiada de corais pequenos, um búzio pequeno, uma verônica de metal amarelo - tudo a tado num cor đão de seda" (L. Reg. 2G, matr. 1100).
}

Esta evidência de sincretismo religioso tinha a intenção óbvia de garantir proteção ao abandonado, partisse ela de que santo ou orixá partisse, muito ao gosto da religiosidade popular brasileira, estruturada ao longo do processo secular de nossa formação histórica.

As manifestações não cristãs, de incidência crescente na década de 1860 , motivaram uma campanha por parte da igreja, que submeteu a religiosidade popular a manifestações concernentes à religião católica, oficial e única reconhecida até a República. Búzios, contas e figas foram substituídos pela pomba do Divino Espírito Santo, à época de especial devoção, e eventualmente acompanhada de verônicas ou medalhas, e já na década de 1870 novamente acrescida de símbolos afro-brasileiros, a exemplo do que ocorre até nossos dias.

Digno de registro é a riqueza material contida nos adereços de identificação. Mais de meia centena de crianças trouxeram objetos de ouro ou prata, como: correntes, figas, chaves, medalhas, aros e moedas. Haveria ainda certa fartura de ouro? Ou fazia-se acompanhar a criança com o que de melhor se possuía, numa tentativa de indenizar a Santa Casa pela criação que lhe daria? 
Estes objetos eram recolhidos ao cofre da Santa Casa e acompanhavam a criança em caso de adoção, criação ou retorno ao lar.

2. Comunicação escrita. Uma em cada três crianças, em números redondos, vinha acompanhada de mensagem escrita, que ia desde a carta correta em ortografia e apresentação, ao simples bilhete rabiscado em tira de papel de embrulho ou de cigarro. Cuidadosamente transcritos nos Livros de Registro, fornecem talvez o material de mais rico conteúdo sociológicco. Traduzem sentimentos de fé, esperança, angústia, desespero, ingenuidade, subse rviência ou arrogância. São indicadores do grau de cultura, de maior ou menor posse material, de dependência econômica, da sanção social estabelecida e outras tantas situações tidas e consagradas pela sociedade cristãpatriarcal oitocentista. Exemplos falam mais claro que explicações:

"Esta criança está batisada, chama-se- Ricardo" (L. Reg. 1G, matr. 42). Bilhetes como este, que acompanhou a criança exposta em 5:10.1839, têm inúmeros similares. O nome era o mínimo de identificação que se poderia esperar para a criança regeitada pelos pais e pela sociedade, mas nem todas tiveram esta sorte. Informar se a criança estava ou não batisada (geralmente não estava), traduzia o cuidado mor de trazer o pagãozinho ao rebanho da igreja católica.

Mais de meio milhar de bilhetes solicitam padrinhos para o menor, in dicando também o nome a ser dado à criança. A madrinha (ou "protetora") mais solicitada, com 255 afilhados até o século XX, foi Nossa Senhora, invocada por N. Sra. da Misericór dia, da Conceição, do Rosário, das Dores, da Glória, de Belém e Mãe de Deus. Seu parceiro mais habitual no batismo, solicitado ou não em bilhete, era algum funcionário graduado da S. Casa, como o administrador, o provedor ou o mordomo da Casa dos Expostos.

Após Nossa Senhora, o mordomo e a regente da Casa dos Expostos eram os mais solicitados para padrinhos, pela proteção direta que disso poderia advir à criança, como no caso de Domingos, abandonado em 11.17.1863 com uma carta dirigida à regente nestes termos:

"A infeliz mãe desta criança requer que V.Sa. seja a madrinha dela e pede que the tenha toda a atenção e amizade como se fosse seu próprio filho, que se suas circunstâncias mudarem de face, terá V.Sa. o prazer de conhecer quem é a infeliz mãe: hoje por suas tristes circunstâncias vê-se na obrigação de retirar-se dele com bem dor de seu coração" (L. Reg. 2G, matr. 1150).

Freqüente também era a escolha de casais da comunidade para padrinhos. Estes só muito excepcionalmente se furtavam a este ato de caridade cristã, e quando isto acontecia, era tão insólito que constava como observa- 
ção no Livro de Registro, junto aos dados da criança. Esta obrigação de consciência diminue com a proclamação da República, que separou Igreja e Estado, tendo a Santa Casa que recorrer a seus funcionários para batisar as crianças abandonadas. A partir da República, o próprio número de expostos decresce, conforme pode ser visto no gráfico anexo.

A guerra, fator de desagregação social e familiar, levou muitas crianças à Roda dos Expostos. Assim, em 5.2.1840, em pleno período farroupilha, o casal Maria e Ricardo de Oliveira Nunes encontraram um menino abandonado à porta de sua residência com o seguinte bilhete:

\begin{abstract}
"Vai este inocente procurar sua proteção como filho de um pai ingrato que desconhece a natureza e de uma mãe infeliz que se vê privado de the poder prestar o agasalho maternal..." (L. Reg. 1G, matr. 52).
\end{abstract}

A criança, levada à Casa da Roda, faleceu três dias mais tarde, talvez em decorrência da miséria social que a cercava.

No mês imediato, um menino pardo foi exposto em casa da preta forra Maria Joana da Conceição, moradora à rua do Arvoredo, em frente ao quintal do palácio. Um bilhete informava ser filho da parda Bernardina, mulher do soldado do 3 ? Batalhão que se achava em campanha. A mãe morrera de parto e Maria Joana, sem recursos, levou a criança à Roda, com bilhete e tudo (L. Reg. 1G, matr. 57).

Ain da durante a guerra, a 21.3.1844, foi abandonado o menino João, com dois meses de idade. Um bilhete dizia ser filho do capitão João Correa Vaz, pedindo que no batismo lhe fosse dado o nome do pai. Padrinho da criança veio a ser o coronel Bibiano José Carneiro da Fontoura, que dois anos antes fora Provedor de Santa Casa (L. Reg. 1G, matr. 236 e FARIA, 18).

Ainda durante a Revolução Farroupilha a Casa da Roda foi procurada pelos pais de Rafael, a 1.5.1840, acompanhado de bilhete explicando que

"As melindrosas circunstâncias privam-nos, autores de teus dias, de
criar-te e cobrir-te de carícias..." (L. Reg. 1G, matr. 50).

A Roda era também buscada em casos de enfermidade, como no caso de Aspácia:

"A pobre criancinha está doente e a mãe não tem leite. Deus a protegerá e a caridade dos homens" (L. Reg. 2G, matr. 957, em 18.3.1859). 
A criança se salvou, sendo restituída aos pais que a procuraram dois an os mais tarde, indenizando a Santa Casa.

O fator primordial de abandono de menores, acreditamos, foi o preconceito social, a par de precária situação econômica. A mãe solteira se via desamparada em meio à sociedade patriarcal e machista, só lhe restando apelar para a caridade pública, sonhando com um amanhã melhor, com a "infeliz mãe" de Camilo que em 12.11.1864 se viu

"na acerba necessidade de lançar para longe de si um filho querido até que o decurso do tempo permite um resgate" (L. Reg. 2G, matr. 1213).

Camilo faleceu com pouco mais de um ano de vida, sem ter sido procurado pela mãe.

José foi exposto em 7.1.1862 acompanhado da súplica materna:

"Forçada por circunstâncias impossíveis de relatar, imploro a V.Sa. desse pio estabelecimento a proteção para o infeliz que este acompanha..." (L. Reg. 2G, matr. 1072).

Caso interessante é o da menina Lina, branca, abandonada com uma semana de vida, em 1.10.1895, à porta da residência de Joaquim Antonio Nunes, à rua Riachuelo, 341, com um bilhete nominal à dona da casa:

\begin{abstract}
"Dona Lina. É uma mãe infeliz que vem trazer-vos e fruto de suas entranhas. Fui iludida, a sociedade em que vivemos não aceita estas ocorrências da vida e eu não posso criar minha filhinha. Eu a lanço junto ao vosso bom coração e fico certa que não repelireis de vossa proteção a inocentinha que não tem culpa da falta de sua desgraçada mãe. Peço-lhe do íntimo da alma que façam esta esmola que perante Deus mais os elevará e que não ficará sem uma recompensa do céu. Ela nasceu no dia 23 de setembro (dia de S. Lino) e vos peço que com vosso digno esposo sejais os padrinhos. Por Deus vos peço não regeiteis o meu anjinho, aceitai a minha filhinha em paga Deus the dará toda a felicidade. Sou uma infeliz mãe, pois tenho esconder o fruto de meu amor, a minha vergonha, aceitai pois para vós este inocentinho que rogará sempre a Deus por vós uma mãe reconhecida" (L. Reg. 12P. matr. 2307).
\end{abstract}

Os sentimentos que esta carta transmite são tão confusos quanto os dos destinatários que, recusando inicialmente receber a menina, encaminharam-na à Casa da Roda, mas, reconsiderando, acabaram por batisar e criála. 
Liberdade é sentimento forte que os pais desejam transmitir aos filhos. Em 4.3.1863, antes da lei do Ventre Livre, surge assim o apelo de uma provável mãe forra, preta ou mulata:

"Já está batisada, chama-se Leopoldina, nasceu livre" (L. Reg. 2G, matr. 1125).

A maioria das crianças expostas não permanecia na Casa da Roda, mas era encaminhada a criadores ou criadeiras, moradores em Porto Alegre ou municípios vizinhos, num círculo de até $200 \mathrm{~km}$ de distância. Mães como a da menina abandonada em 9.9.1959 preferiam criação na Roda e pediam bom tratamento (L. Reg. 2G, matr. 973), talvez para ficar mais próxima à filha e eventualmente poder vê-la na missa dominical da Capela Senhor dos Passos, aberta ao público; talvez porque a Santa Casa inspirava mais confiança, uma vez que criadeiras houve que barganhavam em proveito próprio o dinheiro da criação e maltratavam as crianças.

A maioria dos bilhetes ou cartas estavam redigidas em tom de rogo ou súplica, traduzindo humildade própria da pessoa desamparada cultural, social e economicamente. Mas havia também autores que se julgavam com direitos e, escrevendo com desenvoltura, mais impunham que pediam, como no caso da menina abandonada em se tembro de 1859:

\begin{abstract}
"Recomendação. Esta criança é fillha de família decente e que vai por ora para esta beneficiente casa. Se chamará Maria do Carmo. Sua madrinha será a prote tora Nossa Senhora do Carmo e seu padrinho o senhor... (o Livro de Registro não transcreveu o nome, talvez porque não houvesse indicação); isto pede-se exato cumprimento por ser promessa feita. Roga-se mais todo o desvelo possível e que seja criada na Roda porque aí se demorará muito pouco tempo" (L. Reg. 2G, matr. 972).
\end{abstract}

A menor não permaneceu na Casa dos Expostos, não foi procurada e em fins de 1863 foi entregue para criação ao casal Antonio Mendes Totta.

Nos bilhetes não faltava também a prepotência militar, como no caso da menina exposta em 4.12.1863:

"Esta menina é filha de capitão e pede que seja tratada como tal e que botem o nome de Francisca Ferreira e que seja padrinho Luis de tal e sua filha Luisa, moradores na rua do Rosário em frente à igreja" (L. Reg. 2G, matr. 1169).

Diga-se de passagem que a Santa Casa, que se esmerava em atender os pedidos que the eram dirigidos, deu à menina o nome de Adelaide e padri- 
nhos diversos dos pedidos!

Se uns usavam e abusavam da Santa Casa, outros a elogiavam, como quem abandonou o menino Luis, a 11.10.1854:

"Deus te salve, ó casa santa

Deus te salve, ó caridade

Aqui me vieram botar

Por causa da necessidade" (L. Reg. 1G, matr. 763).

Nota-se que a cultura não esteve ausente da Casa da Roda, fato que merece registro se considerarmos as raras escolas e o alto grau de analfabetismo reinantes. "Belendengue" foi um poeta irresponsável, ou no mínimo sonhador, que em 17.10.1859 abandonou à caridade pública o menor Manoel, acompanhado de uma quadrinha na qual pedia o padrinho:

\author{
"Seja seu nome Manoel \\ Para bem se conhecer, \\ Sendo padrinho o Coruja \\ Por assim eu querer"' (L. Reg. 2G, matr. 979).
}

Se a simpatia de Belendengue era dirigida ao grande intelectual, o professor e historiador Antônio Alvares Pereira Coruja, não sabemos, mas o padrinho de Manoel foi Joaquim Antonio Pereira Coruja. Manoel faleceu com um ano apenas, mas a quadrinha ficou como registro de uma socie dade patriarcal que possibilitava ao pai se desfazer de forma lírica do fruto indesejado de seu romantismo irresponsável.

Cabe aqui lembrar que a Santa Casa, apesar de inúmeros senões, teve por vezes êxitos grandiosos em sua missão de atendimento ao menor abandonado. Tal é o caso da menina abandonada às 6,30 horas da manhã fria de 11 de julho de 1847 com um bilhete lacônico apenas indicando-lhe o nome - Luciana Maria da Silva - e um enxoval pobre constando de

1 camisa de panhino, 1 coeiro de baeta encarnada, 1 mantilha de baetilha encarnada, 1 cinteiro com auréola encarnada, 1 lenço branco com renda roxa, 1 timão de chita, 1 timão de baeta encarnada e 1 touca de Iãzinha roxa com forro azul.

No dia imediato Luciana foi entregue à criadeira Justina Cân dida da Silva, moradora na Praça do Portão e batisada em 27.12.1847 por Gaspar Pereira Viana e Clara Soares Paiva. Quando completou 8 anos, a cria deira optou por permanecer com ela, já sem remuneração da Santa Casa. (L. Reg. 1G, matr. 377). 
Luciana estudou e casou, tornou-se professora e escritora, oradora e feminista, primeira mulher integrante do seleto grupo de intelectuais do Partenon Literário. Batalhou pelo abolicionismo, ela que fora salva do abandono material e moral. Por sua obra pioneira, Luciana de Abreu - que morreu tuberculosa com apenas 33 anos de idade - é hoje nome de rua e de educandário em Porto Alegre, além de patrona da cadeira no 5 da Academia Literária Feminina do Rio Grande do Sul, fundada na mesma cidade em 12 de abril de 1943 e com atividade inin terrupta desde então.

Para finalizar, queremos trazer à tona o registro de José, o recém-nascido exposto na Roda à noite de 2.8.1864, acompanhado de modesto enxoval e de uma poesia que foge aos padrões das mensagens escritas que a Casa dos Expostos recebia. A autora, que não assina, mas coloca local e data, mostra ter noção de versos alexandrinos, de rima e ritmo, portadora de cultura bem acima do usual na época. Quem era? O bibliófolo Pedro Leite Vilas Boas não sabe identificar esta poetisa icógnita de Gravataí, bem como os componentes do CIPEL (Círculo de Pesquisas Literárias de Porto Alegre), especialistas em assuntos sul-rio-grandenses. Fica aqui o desafio aos leitores, informando que o filho de tão ilustre mãe icógnita foi criado por Francisco Caetano Ferraz, morador em Por to Alegre (L. Reg. 2G, matr. 1198):
A uma mãe desolada aten dei
Do leito de angústias curtida de dores Implorò favores para um anjo querido O pranto que corre, meus olhos escurecem
A mão estremece... desvaira o sentido

E que faltam as forças à mãe infeliz Não sabe o que diz, soluça e suspira... Quer escrever, pedir, suplicando... Mas pára chorando, hesita, delira...

Meu Deus, piedade! Guia minha mão...

Meu Deus, compaixãol Preciso escrever...

Traçar estas linhas, pedindo um Asilo...

Nem sei o estilo, prá isso fazer!

Eu era uma virgem, mui frágil, bem sei

Protestos escutei... e, amor me matou

Eu era inocente, qual pomba mimosa

E, māo cavilosa o punhal me enterrou. 
E agora o que resta desse amor violento!

Resta o tormento, o opróbio... a vergonhal

E esta criança que a vós vos entrego

Tão fraca .. tão linda... tão bela e risonha.

Não está batisada, podeis tal fazer

E mesmo escolher um nome qualquer

Peço somente, padrinhos, envim:

Domingos Martins ${ }^{1}$ e sua mulher.

De novo implorando aqui finalizo

Se vos penaliza, atendei-me senhores:

Aceitai o infeliz - o pobre inocente

Deixai-me demente curtir minhas dores.

Aldeia dos Anjos [Gravataí], 19 de agosto de 1864

\section{NOTA}

${ }^{1}$ Domingos Martins Pereira e Souza, administrador da Santa Casa, e sua mulher, Dina Leopoldina Pereira de Souza.

*Pon tifícia Universidade Católica do Rio Grande do Sul

Faculdade dos Meios de Comunicação Social

90.620 Porto Alegre - RS 


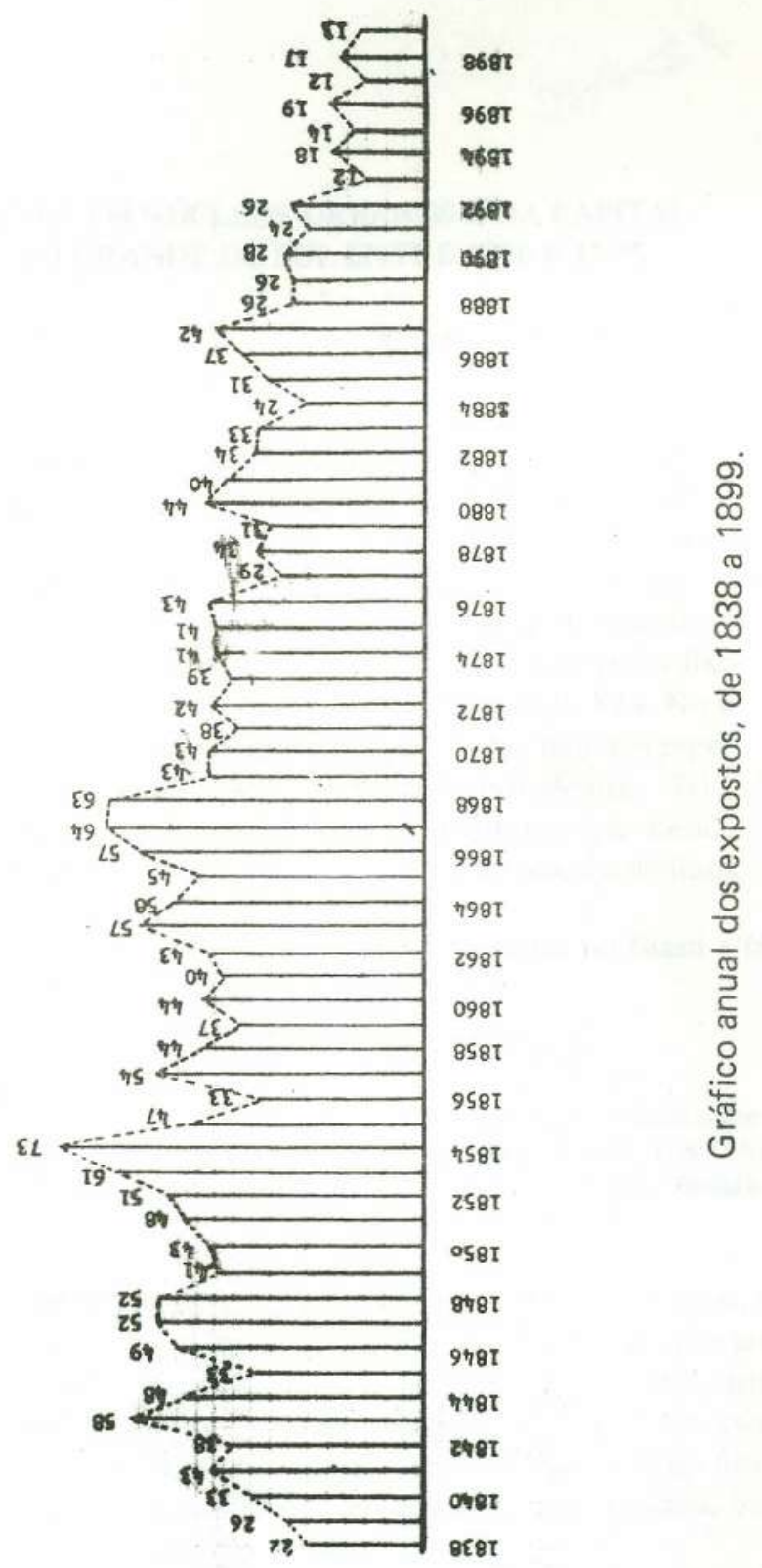

